\title{
The Wickenburg consensus of 1988 and the new MBBS curriculum of today
}

\section{Sethuraman K.R*}

Department of Medicine, Faculty of Medicine, AIMST University, 08100,Semeling, Bedong, Kedah, Malaysia.

For Correspondence

${ }^{*}$ Dr Sethuraman K R,

Email:dean.aimst@gmail.com Date of

Submisssion: 06-11-2018

Acceptance: 07-12-2018

Access this article online

Quick Response Code
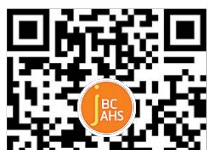

口ifyd

https://www.jbcahs.org

E-ISSN: 2581-6039
"Coincidence obeys no laws and if it does, we don't know what they are." - Roberto Bolaño

Strangely, when the Medical council of India recently released the new MBBS curriculum, it coincided with the $30^{\text {th }}$ anniversary of the Wickenburg Dialogue 1988, which was a 4-day conference sponsored by the Kaiser Foundation, in which the future of medicine and medical education were discussed in depth by 39 physicians, mostly academic and 6 non-physicians. ${ }^{1}$

The Wickenburg group's consensus document attributed traditional academic medicine's restricted views of human health and disease to three main factors:

1. The medical profession's ignorance of its own history and of the importance of humanities in medical practice.

2. A misguided restriction of the boundaries of Medicine to narrow bio-medical paradigm.

3. A false notion in academic medicine that only technologybased solutions and the practice of such technologies constitute medical science.

In White's opinion, it was more and more of know-how rather than know-why. ${ }^{1}$ $\mathrm{He}$ also wrote rather strongly that the 'unwillingness of modern physicians to elicit, listen and understand the patient's life-world was a medical disgrace.
The conference's focus was based on a monograph by Odegaard, of the University of Washington, titled 'Dear Doctor' ${ }^{2}$ and on the landmark articles of Engel, who had proposed his model in $1977^{3}$ and later highlighted its clinical applications. ${ }^{4}$ This model goes beyond the narrow limits of biomedical sciences to include sociology, anthropology etc. Incidentally, the term 'biopsychosocial' was first coined by Roy Grinker - a neurologist and psychiatrist - in 1954, long before Engel. ${ }^{5}$

Wickenburg consensus declared that the biomedical model of $17^{\text {th }}$ Century, which had been the basis of teachinglearning in the medical schools and of medical practice, needed to be replaced by the model for the later part $20^{\text {th }}$ Century and beyond.

Eight broad initiatives were suggested by the group to define the task of medicine more clearly:

1. improve teaching and assessment of "patient-centred interviewing" and communication skills

2. increase the emphasis on the behavioural sciences in medical curricula

3. review the place of primary care in current practice

4. stress the importance of the placebo and Hawthorne effects, and of spiritual factor (Factor X) in the healing process 
5. widen the perspective of the physicians, who have narrow biomedical education focussing on the "know-how", to also include the "know why" from perspectives

6. show concern about the problem of pejorative labelling of the patients and diseases by the medical students and professionals (including those preparing disease lists such as the ICD-10)

7. promote the development of a national agenda on education for the health professions

8. address remedies for the three scandals in Medicine, viz., the use of dehumanising and pejorative terms to describe patients; the use of 'seminar room rounds' instead of the bedside rounds by the consultants; and the lack of formal education and assessment of integrity, respect, communication and compassion.

Using a validated and scientific approach to patientcentred communication practices can give us more robust evidence to practice humanistic medicine. We can conduct more rigorous studies to find better patient-centred clinical practice behaviours. ${ }^{6}$

Three decades ago, in 1988, the Wickenburg consensus had given a clarion call for ushering in profound changes to the way we perceive and practice medical education and clinical practice. Presently, in 2018, the Medical Council of India has released the New Curriculum for MBBS, to effectively address these concerns by broadening the curricular focus to include development of positive attitude, communication skills and ethical and professional behaviour. ${ }^{7}$ It is the earnest hope of enlightened patient-centred medical educators that this would usher in the much needed transformation of medical education and medical practice in the near future

\section{CONFLICTS OF INTEREST}

\section{None}

\section{References}

1. Kerr L. White (Ed) The Task of Medicine: Dialogue at Wickenburg (conference, Wickenburg, Ariz, May 1987), Menlo Park, Calif, Henry J. Kaiser Family Foundation, 1988. p 35.

2. Odegaard CE. Dear Doctor: A Personal Letter to a Physician. Menlo Park, Calif: The Henry J. Kaiser Family Foundation; 1986:165

3. Engel GL. The need of a new medical model: a challenge for biomedicine. Science 1977;196:129-36

4. Engel GL. The clinical application of the biopsychosocial model. Am J Psychiatry 1980;137:5.

5. Ghaemi SN. The rise and fall of the biopsychosocial model. (editorial) Brit J Psychiatry 2009; 195, 3-4.

6. Smith RC, Fortin AH, Dwamenaa F, Frankel RM. An evidence-based patient-centered method makes the biopsychosocial model scientific. Patient Education and Counseling 91 2013; 265-70

7. Medical Council of India. Competency Based Under Graduate Curriculum. Available at https://old.mciindia.org/InformationDesk/ ForColleges/UGCurriculum.aspx (accessed on 06 October 2018) 